\title{
Pseudoaneurysm following Surgical Resection of Craniopharyngioma: What Is the Best Management?
}

\author{
Francisco Marco del Pont ${ }^{1}$ Juan Francisco Villalonga ${ }^{1}$ Amparo Sáenz ${ }^{1,2}$ Guido Caffaratti ${ }^{1, \odot}$ \\ Santiago Condomi Alcorta ${ }^{1}$ Andrés Cervio ${ }^{1}$ \\ ${ }^{1}$ Departamento de Neurocirugia, Fleni, Buenos Aires, Argentina \\ 2Departamento de Neurocirugia, Hospital de Pediatria Juan P. \\ Garrahan, Buenos Aires, Argentina \\ Indian J Neurosurg 2021;10:148-151.

\begin{abstract}
Address for correspondence: Guido Caffaratti, MD Departamento de Neurocirugia, Fleni, Montaneses 2325, ZP 1428, Buenos Aires, Argentina (e-mail: guidocaffaratti@gmail.com).
\end{abstract}

\begin{abstract}
Keywords

- carotid artery injuries

- craniopharyngioma

- pseudoaneurysm

- postoperative complication

- aneurysm

Craniopharyngiomas are benign tumors of the sellar and parasellar region for which surgical resection remains the treatment of choice. There are many publications on the most frequent postoperative complications, but few reports on subclinical lesions affecting the arteries of the circle of Willis, despite their high morbidity and mortality rate. Trauma-induced aneurysms are infrequent, representing less than $1 \%$ of intracranial aneurysms. latrogenic intracranial pseudoaneurysms are a subtype of surgically induced aneurysms developed as a result of direct injury to the arterial wall or after dissection of tumors adherent to the vessel adventitia. The natural history of these lesions is not well known because their incidence is extremely low. We report two cases of postoperative aneurysms of the internal carotid artery after craniopharyngioma resection and a brief review on the management of such lesions.
\end{abstract}

\section{Introduction}

Craniopharyngiomas are benign lesions of the sellar and parasellar region. More frequently observed in children, their incidence in adults is low, reaching 0.5 to 2 cases per million per year. ${ }^{1,2}$

Although associated with elevated postoperative morbidity, surgery remains the treatment of choice for these tumors. ${ }^{2}$ A subclinical lesion of a neighboring artery is a rare and potentially severe postoperative complication, reported in isolated cases. ${ }^{3,4}$

Trauma-induced aneurysms account for less than $1 \%$ of intracranial aneurysms. Iatrogenic pseudoaneurysms are a subtype of such aneurysms that develop as a result of direct injury to the vessel or secondary to dissection of tumors attached to the vessel adventitia. ${ }^{5}$ The natural history of these aneurysms is uncertain.

We present two clinical cases of this complication and discuss its management possibilities based on the literature.

\section{Case 1}

A 39-year-old man presented with bitemporal heteronymous hemianopsia, weight gain, and decreased libido. Magnetic resonance imaging (MRI) of the brain revealed a retrochiasmatic multicystic suprasellar mass, in intimate contact with both internal carotid arteries (ICA) ( - Fig. 1A).

Tumor resection was performed through a right subfrontal approach. Postoperative MRI at 3 months showed neither tumor residue nor vascular alterations (-Fig. 1B). At 6 months, the patient started with visual deficit and a new MRI showed dilatation of the supraclinoid segment of the right ICA (-Fig. 1C). Digital angiography (DA) revealed a fusiform aneurysm with a vesicle attached to the dome ( - Fig. 1D, E). Endovascular treatment (coils plus flow diverter) of the lesion was performed, and a satisfactory occlusion was observed on follow-up DA ( - Fig. 1F). published online April 30, 2021
DOI https://doi.org/

10.1055/s-0041-1729462 ISSN 2277-954X
(C) 2021. Neurological Surgeons' Society of India.

This is an open access article published by Thieme under the terms of the Creative Commons Attribution-NonDerivative-NonCommercial-License, permitting copying and reproduction so long as the original work is given appropriate credit. Contents may not be used for commercial purposes, or adapted, remixed, transformed or built upon. (https://creativecommons.org/licenses/by-nc-nd/4.0/).

Thieme Medical and Scientific Publishers Pvt. Ltd. A-12, 2nd Floor, Sector 2, Noida-201301 UP, India 

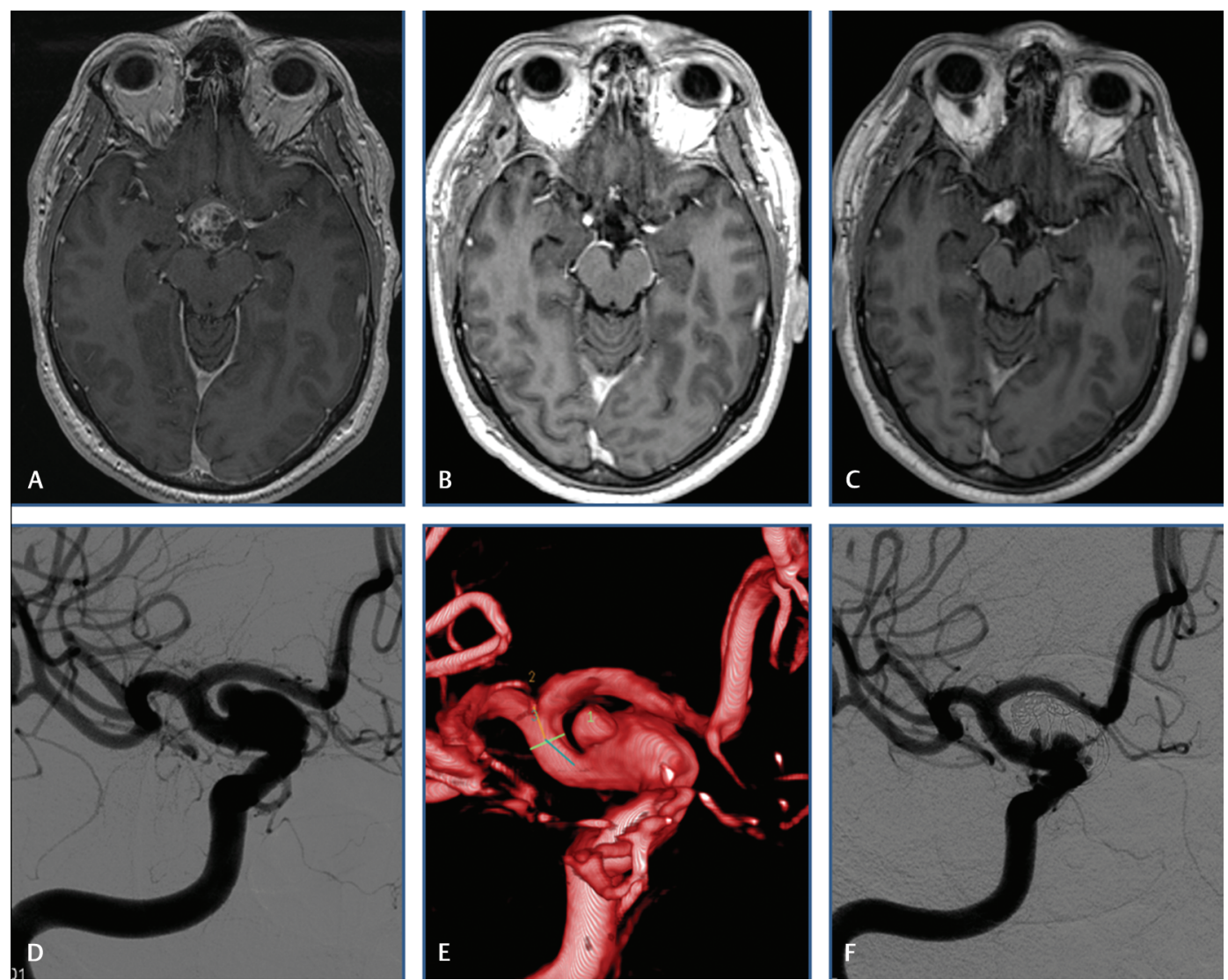

Fig. 1 Case 1. (A) Presurgical brain magnetic resonance imaging (MRI). (B) Postoperative MRI at 3 months without vascular lesion. (C) Postoperative MRI at 6 months with aneurysm of the right ICA. (D) Digital angiography (DA) with fusiform dilation of the internal carotid artery (ICA) and a vesicle attached to the dome. (E) Three-dimensional (3D) reconstruction of abnormal segment. (F) Follow-up images after endovascular treatment.

\section{Case 2}

A 45-year-old woman with a history of subtotal resection of craniopharyngioma through a subfrontal approach in another institution consulted for superior left quadrantanopia. Brain MRI showed a predominantly right-sided mixed cystic and solid suprasellar mass (-Fig. 2A).

Surgery was performed through an endonasal endoscopic approach. Patient outcome was favorable and immediate postoperative MRI confirmed complete resection of the lesion, with no vascular alterations (-Fig. 2B). MRI with angiography at 4 months showed a fusiform dilatation of the supraclinoid segment of the right ICA ( - Fig. 2C, D). Imaging at 24-month follow-up showed no changes in lesion size; consequently, conservative management was adopted ( - Fig. 2E, F).

\section{Discussion}

In a publication by Ciceri et $a{ }^{5}$, from a total of 52 iatrogenic intracranial aneurysms, 43 involved the ICA, with aneurysm subtypes and underlying lesions varying between age groups.

Fusiform lesions of the ICA resulting from craniopharyngioma surgery were predominant among pediatric patients. ${ }^{3-5}$ In a series reported by Sutton et al, ${ }^{3}$ of 31 children diagnosed with craniopharyngioma and operated through a right-sided craniotomy, 9 developed fusiform dilatation of the right ICA after the procedure.

Although the pathophysiology of this entity remains unclear, it is believed that dissection of the tumor from the adventitia of the vessel causes weakening of its wall and subsequent dilatation. The general consensus is that these lesions are stable, with no increased risk of bleeding, ${ }^{5,6}$ and image-based follow-up is considered the best management.

On the other hand, in adult patients, reports of iatrogenic saccular aneurysms after pituitary adenoma resection prevail. ${ }^{7-9}$ Frank et $\mathrm{al}^{9}$ reported a case of a 27 -year-old patient with a pituitary adenoma, operated through a right pterional approach, that 11 months later developed a saccular dilatation of the right ICA which required surgical treatment. Cappabianca et $\mathrm{al}^{8}$ reported a case of a 22-year-old patient with a macroadenoma operated endoscopically, complicated with intraoperative bleeding that later developed a saccular aneurysm of the ICA, managed through an endovascular approach.

Saccular aneurysms would result from direct damage during surgery, with a focal laceration, which would lead to hematoma formation on the vessel wall, detected as a saccular deformity on imaging follow-up. Risk of bleeding is higher in these cases and surgical treatment is recommended. ${ }^{5}$

In the cases we reported, based on their clinical and radiological features, image-based follow-up was instituted. 

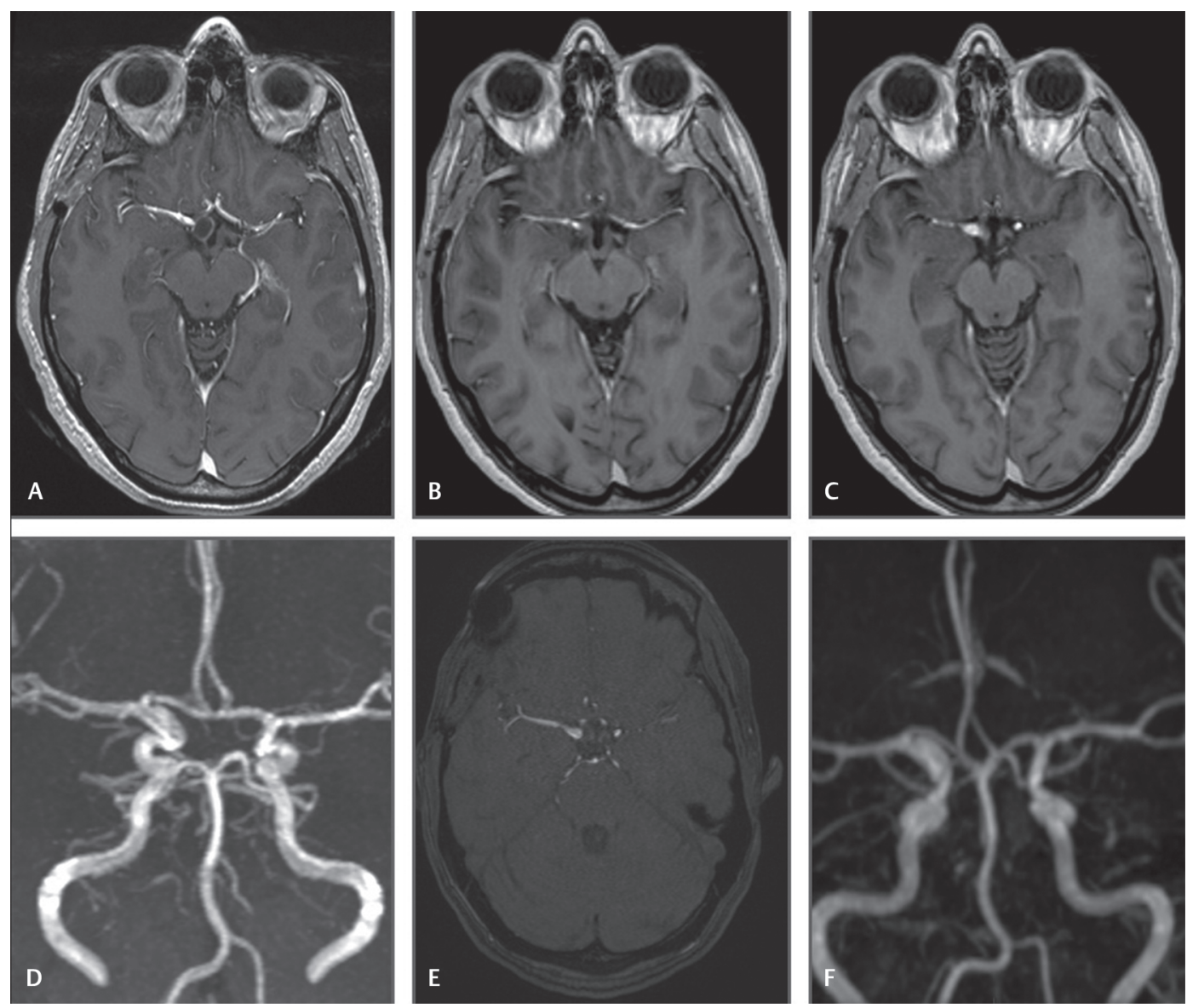

Fig. 2 Case 2. (A) Presurgical magnetic resonance imaging (MRI). (B) Postoperative MRI with no tumor residue or abnormalities in vascular structures. (C, D) Postoperative magnetic resonance angiography (MRA) at 4 months showing fusiform dilatation in a segment of the right internal carotid artery (ICA). (E) MRA 4 months after surgery with fusiform dilatation of the right ICA. (F) Postoperative follow-up MRA at 24 months; vascular lesion shows no change in size.

In the first patient, both a fusiform dilatation and a saccular aneurysm were found. Increase in lesion size during follow-up suggested greater risk of bleeding; hence, endovascular treatment was indicated. In the second case, involving a fusiform aneurysm, the patient continued with image-based monitoring and currently remains asymptomatic.

\section{Conclusion}

While vascular complications are not the first to come in mind after craniopharyngioma resection, they may nevertheless occur. Therefore, strict imaging follow-up is recommended, particularly in tumors showing strong adherence to the vascular wall.

Although the absence of a general consensus regarding the best treatment for these lesions, most authors agree that in the case of fusiform aneurysms, imaging monitoring is reasonable, and treatment would be necessary if growth or onset of related symptomatology are observed. In saccular aneurysms the risk of bleeding would be higher, and prompt surgical treatment should be indicated.

\section{Funding}

None.

\section{Conflict of Interest}

None declared.

\section{References}

1 Erfurth EM, Holmer H, Fjalldal SB. Mortality and morbidity in adult craniopharyngioma. Pituitary 2013;16(1):46-55

2 Fernandez-Miranda JC, Gardner PA, Snyderman CH, et al. Craniopharyngioma: a pathologic, clinical, and surgical reviewHead Neck. 2012 ;34(7):1036-1044

3 Sutton LN, Gusnard D, Bruce DA, Fried A, Packer RJ, Zimmerman RA. Fusiform dilatations of the carotid artery following radical surgery of childhood craniopharyngiomas. J Neurosurg 1991;74(5):695-700

4 Lakhanpal SK, Glasier CM, James CA, Angtuaco EJ. MR and CT diagnosis of carotid pseudoaneurysm in children following surgical resection of craniopharyngioma. Pediatr Radiol 1995;25(4):249-251

5 Ciceri EFM, Regna-Gladin C, Erbetta A, et al. latrogenic intracranial pseudoaneurysms: neuroradiological and therapeutical considerations, including endovascular options. Neurol Sci 2006;27(5):317-322

6 Sutton LN. Vascular complications of surgery for craniopharyngioma and hypothalamic glioma. Pediatr Neurosurg 1994;21(1(Suppl 1):124-128

7 Malik A, Goyal M, Mishra NK, Verma A, Gaikwad S, Mehta VS. Pseudoaneurysm of anterior communicating artery 
following transsphenoidal surgery for craniopharyngioma. J Clin Neurosci 1998;5(4):463-464

8 Cappabianca P, Briganti F, Cavallo LM. de Divitiis E. Pseudoaneurysm of the intracavernous carotid artery following endoscopic endonasal transsphenoidal surgery, treated by endovascular approach. Acta Neurochir (Wien) 2001;143(1):95-96

9 Frank G, Galassi E. Aneurysmal dilatation of ICA after tumor resection. J Neurosurg 1992;76(1):169-170 